\title{
Interpretation of ante-mortem stature estimates in South Africans
}

\author{
M. Steyn ${ }^{a,}$ and J.R. Smith ${ }^{b}$ \\ ${ }^{a}$ Department of Anatomy, University of Pretoria, P.O. Box 2034, Pretoria 0001, South Africa \\ ${ }^{b}$ Ergonomics Technologies (ERGOTECH), P.O. Box 6264, Pretoria 0001, South Africa
}

\begin{abstract}
When human skeletal remains of unknown individuals are analysed, the estimation of ante-mortem stature forms a key part of the report. However, for many people it may be difficult to judge the height of their missing relative in metric values. In this paper, we report on the statures of 2052 black, 483 coloured and 880 white South Africans of both sexes, measured during the last few years. It is shown that the statures of whites are significantly higher than those of the other two groups. The statures of the black and coloured groups are similar. It is proposed that the stature estimates provided in forensic reports are interpreted as tall, medium or short, based on whether they fall in the upper $25 \%$, middle $50 \%$ or lower $25 \%$ of the distribution for the specific population.
\end{abstract}

\section{Introduction}

Estimation of ante-mortem or living stature from the skeleton is a key aspect in the analysis of remains of unknown individuals. A multitude of regression formulae for South Africans (e.g., [1], [2], [3] and [4]) and other populations (e.g., [5], [6], [7] and [8]) have been developed for this purpose. An estimate of ante-mortem stature, along with the assessment of age, sex and race is given in almost all forensic reports on unknown human skeletal remains [9].

The usability of these stature estimates in finding missing individuals or identifying unknown individuals from their remains may, however, be questioned. Stature is not such a stable phenomenon as is immediately apparent. People tend to report their stature as being higher than it actually is, police may record how tall a person says he/she is, and stature may change with age or through time [10] and [11]. Investigating officers may use the reconstructed stature in their search for a missing person, but the truth of the matter is that very few people actually know how tall their missing relative was. They may, at most, be able to say whether he/she was short, medium or tall. This is especially true in developing countries, where people often have a limited concept of metric values.

This brings us to the question of what actually constitutes a person of "short" or "medium" height. For example, in South Africa what may be "medium" stature for a white individual, may indeed be tall for a black South African. The concept of population-specific formulae for skeletal identification purposes for each population is based on the principle that various populations differ in their skeletal proportions (e.g., [9]). In fact, it has been shown that in South Africa, the blacks have shorter and less robust bones than white South Africans [12].

The purpose of this paper is to set standards for interpretation of stature estimates for various South African populations. Data on stature for black, white and mixed origin ("Cape Coloured") populations will be used to determine which reconstructed statures should be interpreted as short, tall or of medium height.

\section{Materials and methods}

The South African population comprises of a diverse and complex mixture of people. Attempts to "group" or "classify" people according to ethnic origin are difficult and fraught with problems, as urban migration, genetic interchange and several other factors may play a role. These difficulties are also not unique to South Africa. Broadly speaking, the South African "white" population had its origin in Europe, with contributions, amongst others, from the Netherlands, Britain, France and Germany [12], [13] and [14]. However, as a result of founder's effect, temporal change and admixture, South African whites have become osteologically distinguishable from their European and North American counterparts (e.g., [12], [14], [15], [16] and [17]). The black population of South Africa comprises of several different tribes, but osteological differences amongst them are not great enough to justify separation [18]. Some variation, albeit small, was observed between the statures of various Bantu-speaking groups [19].

The origin of the so-called "Cape Coloured" group is more complex. During the early years of modern South African history, large-scale intermixture occurred between European settlers, the local inhabitants of the Cape Colony (mostly Khoisan peoples), freed slaves and people from the East. This led to a group of people that was loosely classified in the Apartheid years as "Cape Coloured". 


\section{openUP}

The data used in this study form part of a large data set of various anthropometric measurements of the South African military population, collected by ERGOTECH from 2000 to 2005 . These data are primarily used for ergonomics design and evaluation purposes, such as the sizing of clothes and the design of engineering equipment to optimally accommodate the user population. The sample size for the various sex-race groups range between 237 (females, coloured) and 1208 (males, black) individuals. The volunteers who participated in the study were between the ages of 18 and 56. Although it can be expected that some growth may occur after the age of 18 years, this increase should be small and is not expected to change the data significantly. Stature was measured according to the definition of ISO 7250 [20]; the vertical distance from the standing surface to the highest point of the head (vertex) with the head orientated in the Frankfurt plane and with the subject standing erect with the feet together. Standard anthropometric equipment (vertical anthropometer) was employed for the measurements. All the measurements were conducted by anthropometrists with at least a level 2 qualification from the International Society for the Advancement of Kinanthropometry (ISAK) under the supervision of a criterion anthropometrist (level $4)$.

For the purpose of this paper, statures in the lower $25 \%$ of the distribution are regarded as "short", those in the upper $25 \%$ as "tall" and the remaining, middle $50 \%$ was classified as "average" or "medium". This is an arbitrary division, but the creation of a large "average" group ascertains that those individuals described as short or tall really falls in the upper or lower range of observed statures.

\section{Results}

The mean stature, range and standard deviations for each of the six sex-race groups are shown in Table 1 . The Kolmogorov-Smirnov test values presented in Table 1 indicates that normality can be accepted for all the distributions per group. This is true for even the smallest of the groups, namely the coloured females. As can be seen from Fig. 1 and Fig. 2, the whites from both sexes are taller than those from the other two groups. The mean stature for white males is about $74 \mathrm{~mm}$ taller than for black males and $81 \mathrm{~mm}$ taller than for coloured males, with the female differences being about 65 and $60 \mathrm{~mm}$, respectively. The mean stature for black males is slightly higher than that of the coloured individuals, whilst the mean height for coloured females is taller than that of black females. The differences between these latter two groups are, however, insignificantly small. To determine the significance of the differences between the means, the $t$-test for independent samples was administered to the data. The results are presented in Table 2. The differences between the means indicate that there is no statistical significant difference between the means of black males and coloured males $(p>0.05)$. Similarly, there is no significant difference between the means of the black females and coloured females $(p>0.05)$. However, the means for both black males and coloured males are statistically significantly different from that of white males $(p<0.05)$. Also, there are significant differences between the means of both black females and coloured females when compared with that of white females $(p<0.05)$.

Table 1. Descriptive statistics for the stature of South Africans

\begin{tabular}{|c|c|c|c|c|c|c|c|}
\hline Group & $n$ & Mean & S.D. & Skewness & Kurtosis & Kolmogorov-Smirnov test value & $5 \%$ Critical value \\
\hline \multicolumn{8}{|l|}{ Males } \\
\hline Black & 1208 & 1710.1 & 61.64 & 0.132 & 2.986 & 0.021 & 0.027 \\
\hline Coloured & 246 & 1703.2 & 61.41 & 0.321 & 3.210 & 0.035 & 0.056 \\
\hline White & 288 & 1784.5 & 68.45 & 0.276 & 2.919 & 0.044 & 0.052 \\
\hline \multicolumn{8}{|l|}{ Females } \\
\hline Black & 844 & 1596.0 & 60.83 & 0.038 & 2.617 & 0.024 & 0.032 \\
\hline Coloured & 237 & 1600.7 & 57.77 & 0.012 & 2.950 & 0.054 & 0.057 \\
\hline White & 592 & 1660.8 & 60.80 & 0.006 & 2.838 & 0.025 & 0.037 \\
\hline
\end{tabular}

All measurements are in $\mathrm{mm}$. 


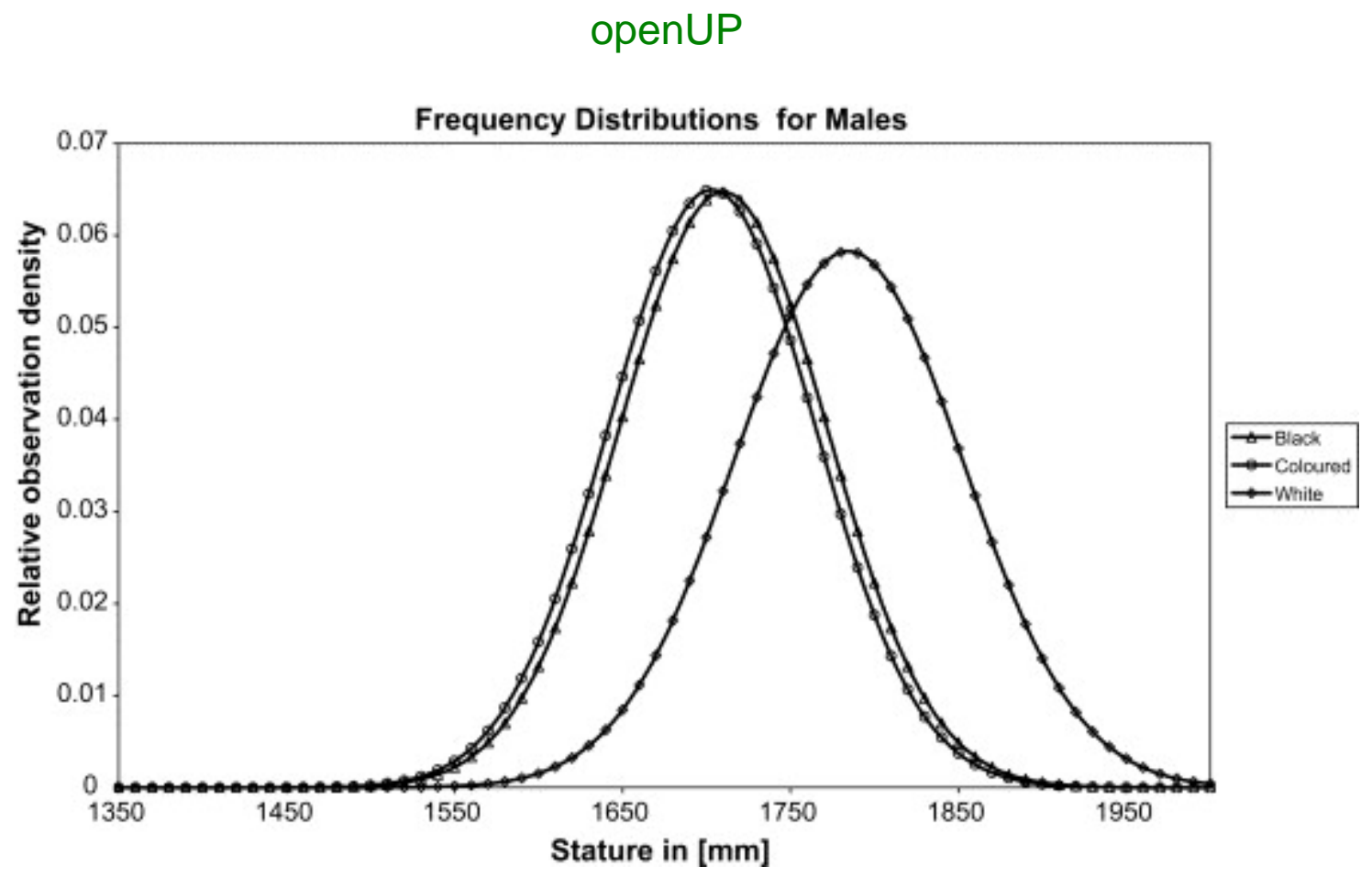

Fig. 1. Frequency distribution for males.

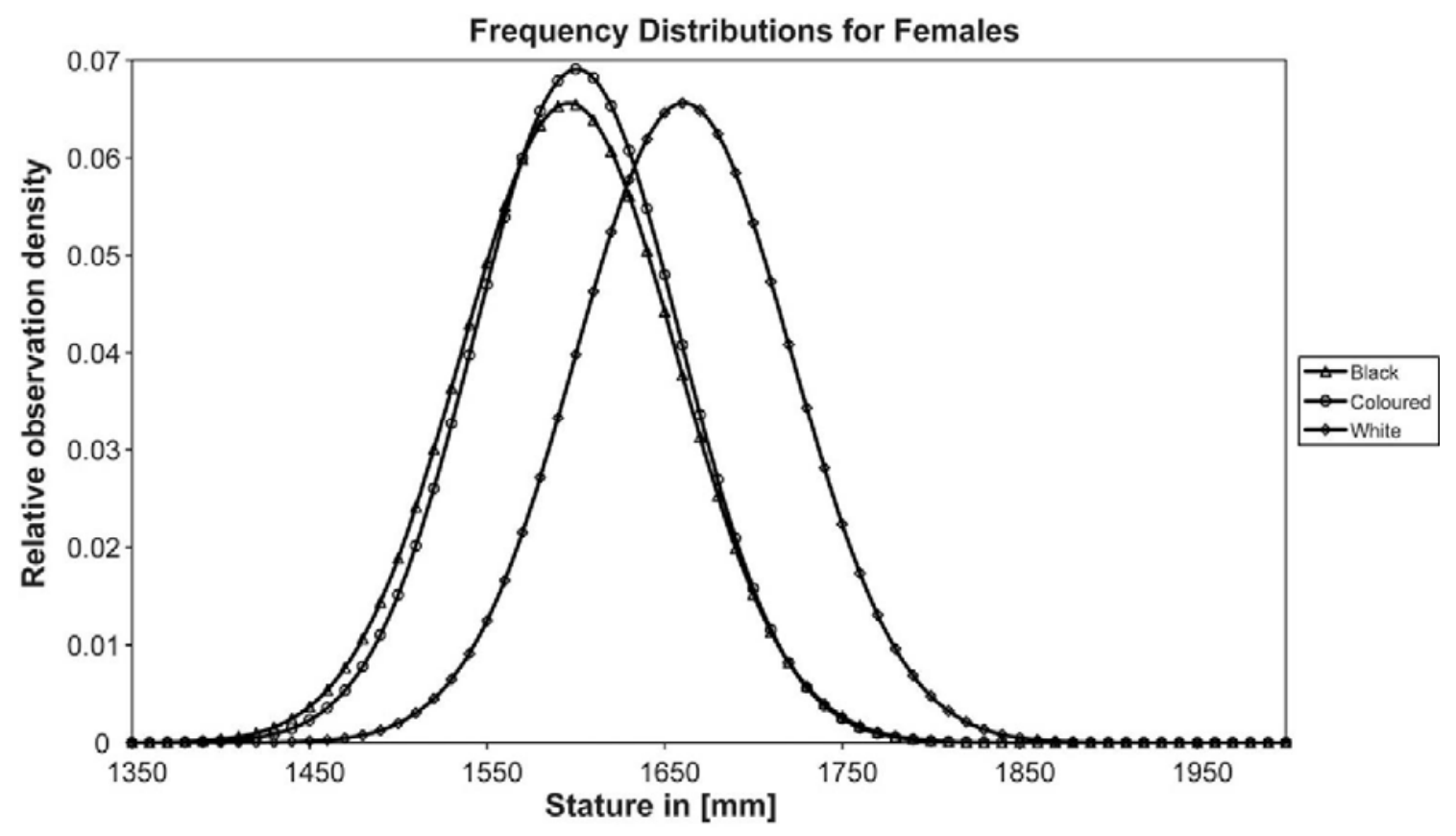

Fig. 2. Frequency distribution for females.

Table 2. Summary of the results of the $t$-tests for independent samples

\begin{tabular}{|l|l|l|}
\hline Groups & $\boldsymbol{t}$-Value & $\boldsymbol{p}$ \\
\hline Black males and Coloured males & -1.6329 & 0.102702 \\
\hline Coloured males and White males & -14.3385 & 0.000000 \\
\hline White males and Black males & -17.9931 & 0.000000 \\
\hline Black females and Coloured females & 1.3676 & 0.171722 \\
\hline Coloured females and White females & -13.0505 & 0.000000 \\
\hline White females and Black females & -20.3527 & 0.000000 \\
\hline Black males and Black females & 42.1537 & 0.000000 \\
\hline Coloured males and Coloured females & 18.8802 & 0.000000 \\
\hline White males and White females & 27.1475 & 0.000000 \\
\hline
\end{tabular}




\section{openUP}

As can be expected, the females of all groups are shorter than the males (Fig. 3, Fig. 4 and Fig. 5). Furthermore, the differences between the means for males and females are statistically different for all the races $(p<0.05)$ (Table 2). The degree of sexual dimorphism [(male mean - female mean)/male mean $\times 100]$ [16] is 6.67, 6.02 and $6.93 \%$ for the black, coloured and white groups, respectively.

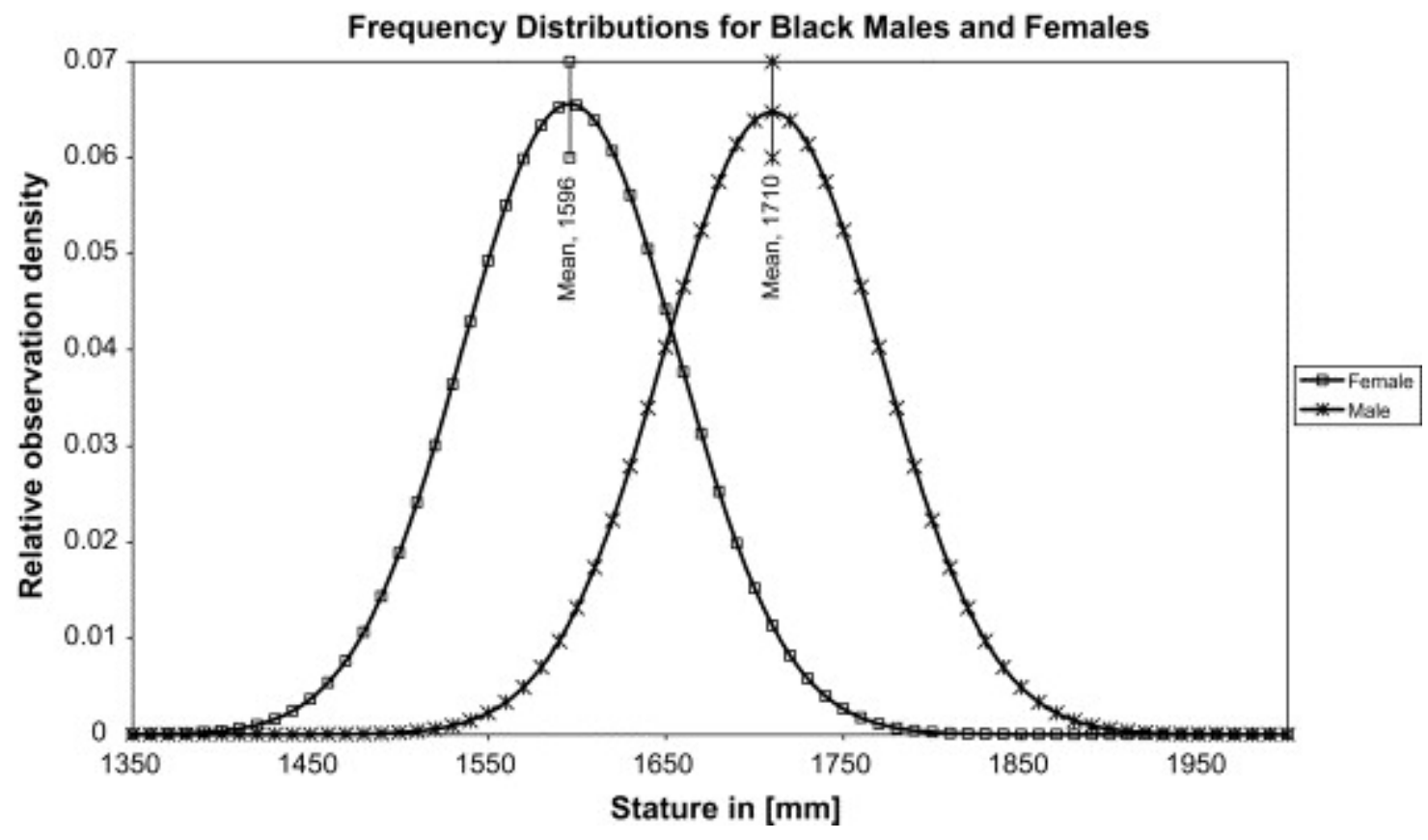

Fig. 3. Frequency distributions for black males and females.

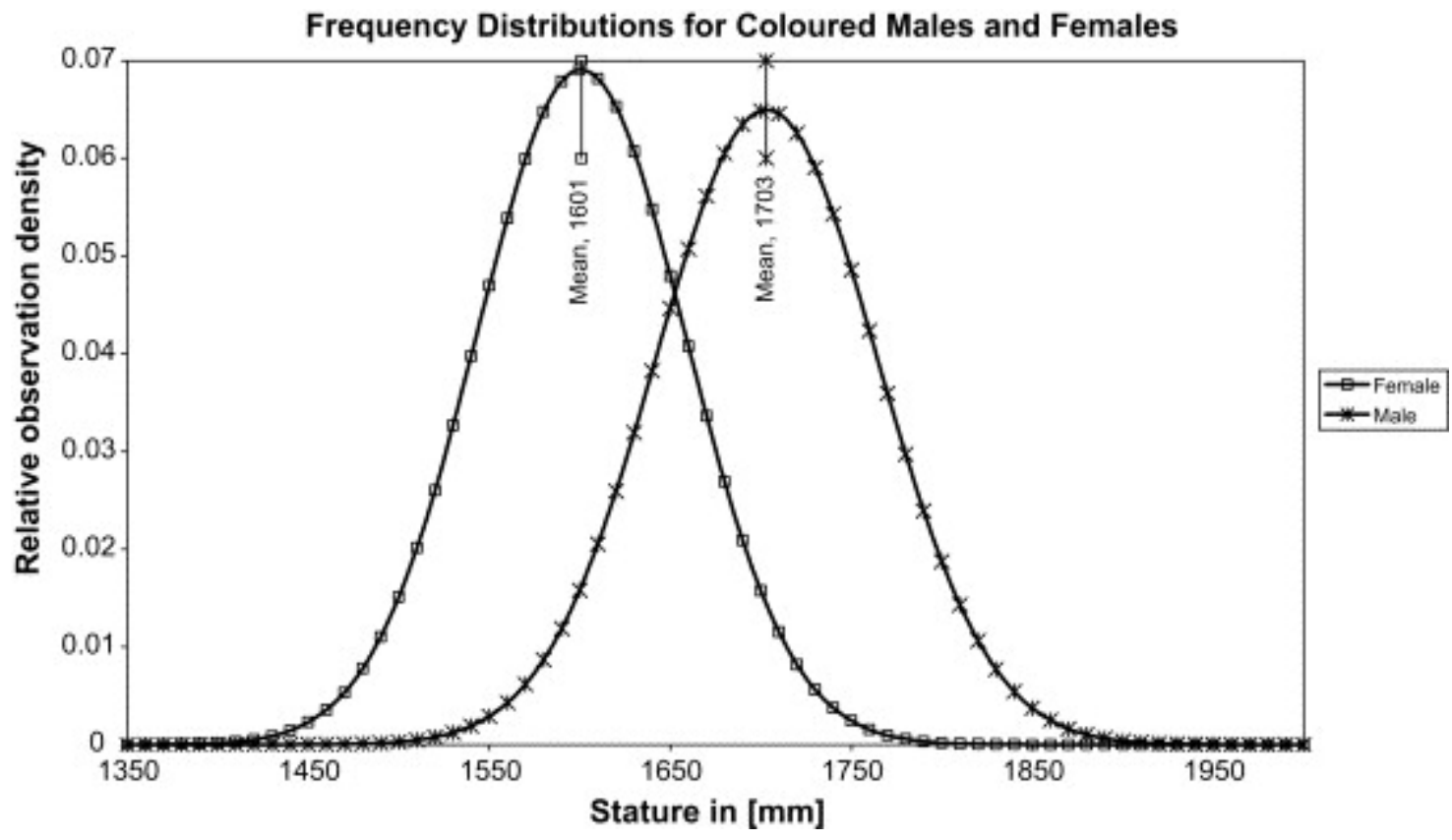

Fig. 4. Frequency distributions for coloured males and females. 


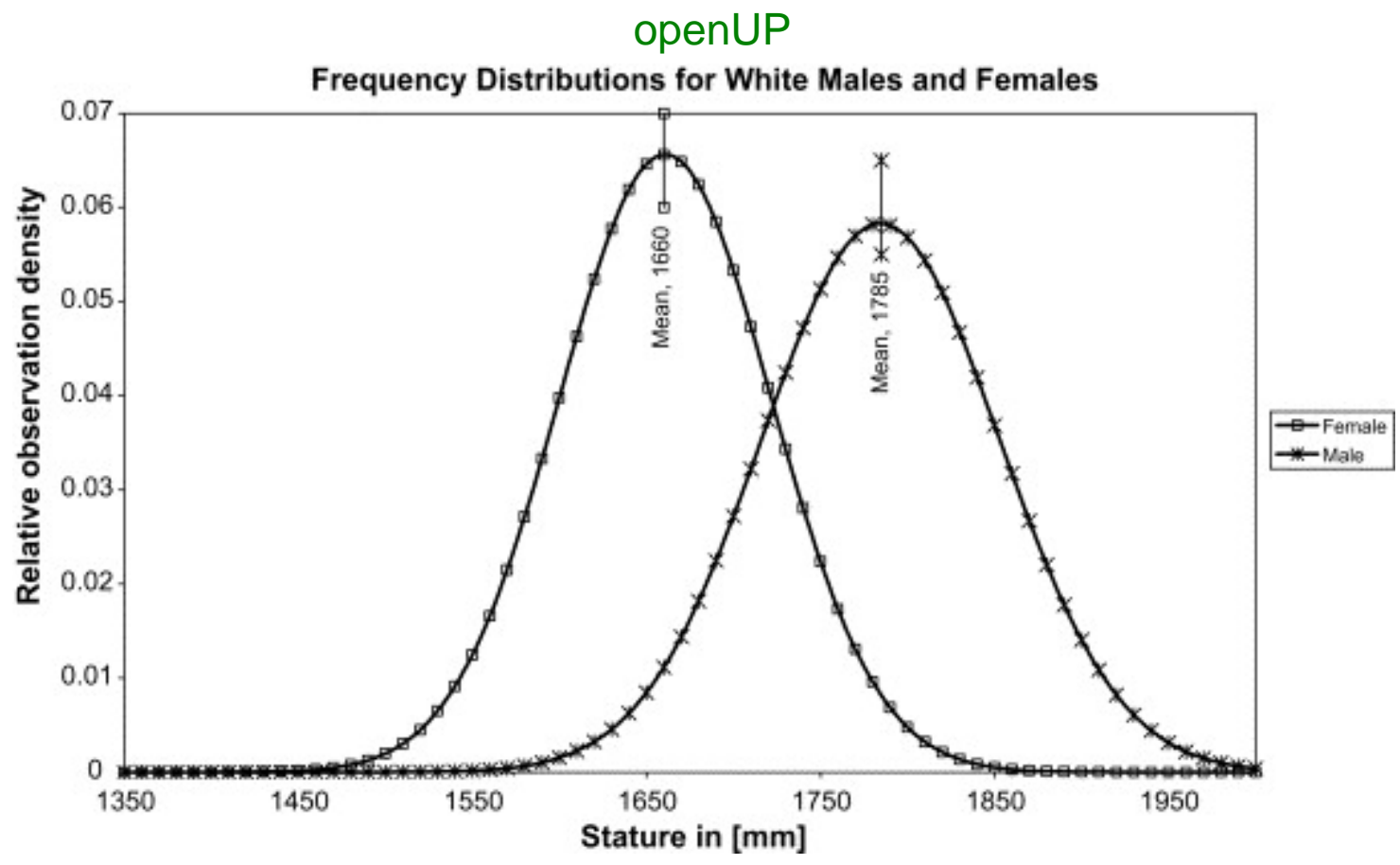

Fig. 5. Frequency distributions for white males and females.

The distribution of the statures of the various groups, by percentiles, is shown in Table 3. According to the proposed divisions for short, medium height and tall, this would mean that for black males, for example, an individual shorter than $1667 \mathrm{~mm}$ would be classified as short, $1667-1752 \mathrm{~mm}$ as medium, and above $1752 \mathrm{~mm}$ as tall. For white females, for example, an individual shorter than $1617 \mathrm{~mm}$ would be described as short, between 1617 and $1702 \mathrm{~mm}$ as average and above $1702 \mathrm{~mm}$ as tall.

Table 3. Percentiles of distribution of statures, with cut-off points at 25th and 75th percentiles

\begin{tabular}{|l|l|l|l|l|l|l|}
\hline & \multicolumn{5}{|l|}{ Percentiles } \\
\cline { 2 - 7 } & $\mathbf{1}$ & $\mathbf{2 5}$ & $\mathbf{5 0}$ & $\mathbf{7 5}$ & $\mathbf{9 9}$ \\
\hline & - & - & - & \\
\hline Males & 1574 & $\mathbf{1 6 6 7}$ & 1708 & $\mathbf{1 7 5 2}$ & 1858 \\
\hline Black & 1575 & $\mathbf{1 6 5 7}$ & 1703 & $\mathbf{1 7 4 5}$ & 1872 \\
\hline Coloured & 1645 & $\mathbf{1 7 3 7}$ & 1780 & $\mathbf{1 8 3 0}$ & 1956 \\
\hline White & & & & \\
\hline & 1467 & $\mathbf{1 5 5 2}$ & 1595 & $\mathbf{1 6 3 9}$ & 1730 \\
\hline Females & 1465 & $\mathbf{1 5 6 0}$ & 1602 & $\mathbf{1 6 3 6}$ & 1740 \\
\hline Black & 1515 & $\mathbf{1 6 1 7}$ & 1661 & $\mathbf{1 7 0 2}$ & 1805 \\
\hline Coloured & & & & \\
\hline White & & & & \\
\hline
\end{tabular}

\section{Discussion}

From the results obtained in this study, it is clear that the statures of the various South African population groups are different. The whites of both sexes are taller than the other two groups, although these two groups (blacks and coloured) are similar to each other. It is proposed that the results here are used to give added value to stature estimates from skeletal remains in forensic reports. For example, an interpretative sentence can be added to the forensic report to state that "this individual was relatively tall in comparison with the rest of his population group". As the reconstructed living statures of individuals can never be $100 \%$ accurate, it may also be advantageous to contextualize a stature estimate into a broad category of short/medium/tall, rather than just quoting a very specific value which may be off by a centimetre or two.

The 25-50-25 division is arbitrary. However, since "tall" or "medium" can be interpreted in different ways by members of the public, it was felt that this division is better than a 33-33-33 division, since somebody who is classified as tall using these guidelines can be expected to really be at the upper end of the normal spread. 


\section{openUP}

It should be noted that all the individuals used in this analysis were measured from 2000 to 2005 . The data are thus new, and pertains to currently living South Africans. Much has been written on secular trend in stature, also pertaining to South Africans (e.g., [14], [21], [22] and [23]). As far as the black population is concerned, Tobias [19] reported that the males were usually of medium stature, which he described as $1600-1700 \mathrm{~mm}$ tall. He argued for the absence of a positive secular trend for this population group [23]. The mean stature for males of $1710 \mathrm{~mm}$ found in the current study may point towards a weak positive secular trend, as proposed by Henneberg and van den Berg [14]. Unpublished data of South African black males in the citizen force, collected in the early 1990s by ERGOTECH, revealed mean statures of $1701 \mathrm{~mm}$ for Zulus $(n=156)$, and $1703 \mathrm{~mm}$ for Northern Sothos $(n=149)$ (source: Republic of South Africa Military standards, RSA-MIL-STD-127 of December 1, 1995). This also supports the possibility of a positive secular trend.

The most recent published statures for South African whites as measured in 1988, quoted by Henneberg and van den Berg [14], were $1793 \mathrm{~mm}$ for males and $1649 \mathrm{~mm}$ for females. This value for males is taller than that found in the current study $(1784.5 \mathrm{~mm})$, However, 746 white male military conscripts measured in the 1990s had a mean stature of $1786 \mathrm{~mm}$ (source: Republic of South Africa Military standards, RSA-MIL-STD-127 of December 1, 1995). This is shorter that the Henneberg and van den Berg data, and similar to the data of the current study. The taller statures for this group recorded by Henneberg and van den Berg may be due to the fact that these authors measured medical students which may all have been of higher socio-economic status, and thus taller. Conversely, the white females in the current study $(1660.8 \mathrm{~mm})$ are taller than those measured in 1988 by Henneberg and van den Berg.

The unpublished 1990s data for coloured individuals indicated mean statures for males of $1651 \mathrm{~mm}$ (source: Republic of South Africa Military standards, RSA-MIL-STD-127 of 1 December 1995) versus the $1703 \mathrm{~mm}$ quoted in the current study. This is also indicative of a positive trend. The figures quoted above make it difficult to comment on the presence of a secular trend, and other factors such as differences in socio-economic status and genetic makeup should be considered. It is also a relatively short period of time, which may be too short to observe any trend. What is clear, though, is that the guidelines given here for somebody being tall, average or short, should be used with caution when interpreting the stature of past populations.

Tobias [19] argued that sexual dimorphism may be lower under unfavourable conditions and vice versa. The degree of sexual dimorphism found in the three populations studied here are very similar, with that of the white group being the highest by a small margin. The sexual dimorphism seen here ranges between 6 and $7 \%$ which is very similar to that reported by Tobias [19], although many of the European populations tended towards $7-8 \%$, and the African populations towards $5-6 \%$. Judged on a superficial level the socio-economic conditions of the three groups investigated may thus be similar, although more research is needed to confirm this.

\section{Conclusion}

In this paper, data from more than 3000 individuals were used to obtain insight into the normal distribution of stature in modern South Africans. It is proposed that these guidelines be used to add value to stature estimates given in forensic anthropological reports, and that researchers from other continents determine similar standards for their populations. In this way, stature reconstructions reported in forensic reports can be assessed in a more meaningful way.

\section{Acknowledgements}

The authors would like to thank the volunteers who participated in the study, as well as the Director Technology Development, Department of Defence, South Africa for permission to use the anthropometric data for this study.

\section{References}

[1] J.K. Lundy and M.R. Feldesman, Revised equations for estimating living stature from long bones of the South African Negro, S. Afr. J. Sci. 83 (1987), pp. 54-55.

[2] M.R. Dayal, Stature estimates from long bones of South African whites using regression formulae. Unpublished M.Sc. dissertation, University of the Witwatersrand, 2003.

[3] M. Bidmos and S. Asala, Calcaneal measurement in estimation of stature in South African blacks, Am. J. Phys. Anthropol. 126 (2005), pp. 335-342. 


\section{openUP}

[4] M.R. Dayal, M. Steyn, K. Kykendall, Stature estimation from the long bones of South African whites, J. Forensic Sci., unpublished manuscript.

[5] M. Trotter and G.C. Gleser, Estimation of stature from long bones of American whites and negroes, Am. J. Phys. Anthropol. 10 (1952), pp. 463-514.

[6] G. Olivier, C. Aaron, G. Fully and G. Tissier, New estimations of stature and cranial capacity in modern man, J. Hum. Evol. 7 (1978), pp. 513-518.

[7] T.D. Holland, Brief communication: estimation of adult stature from the calcaneus and talus, Am. J. Phys. Anthrop. 96 (1995), pp. 315-320.

[8] L. Meadows and R.L. Jantz, Estimation of stature from metacarpal lengths, J. Forensic Sci. 37 (1992), pp. $147-154$.

[9] W.M. Krogman and M.Y. İşcan, The Human Skeleton in Forensic Medicine, Charles C Thomas, Springfield (1986).

[10] T. Sjovold, Stature estimation from the skeleton. In: J.A. Siegel, P.J. Saukko and G.C. Knupfer, Editors, Encyclopaedia of Forensic Sciences, Academic Press, London (2000), pp. 276-284.

[11] C.C. Snow and J. Williams, Variation in premortem statural measurements compared to statural estimates of skeletal remains, J. Forensic Sci. 16 (1971), pp. 455-464.

[12] M. Steyn and M.Y. İşcan, Osteometric variation in the humerus: sexual dimorphism in South Africans, Forensic Sci. Int. 106 (1999), pp. 77-85.

[13] M.Y. İşcan and M. Steyn, Craniometric assessment of population affinity in South African Blacks and Whites, Int. J. Legal Med. 112 (1999), pp. 91-97.

[14] M. Henneberg and E.R. van den Berg, Test of socioeconomic causation of secular trend: stature changes among favored and oppressed South Africans are parallel, Am. J. Phys. Anthrop. 83 (1990), pp. 459-465.

[15] M.L. Patriquin, M. Steyn and S.R. Loth, Metric assessment of race from the pelvis in South Africans, Forensic Sci. Int. 127 (2002), pp. 104-113.

[16] M.Y. İşcan, S.R. Loth and M. Steyn, Determination of racial affinity. In: J.A. Siegel, P.J. Saukko and G.C. Knupfer, Editors, Encyclopaedia of Forensic Sciences, Academic Press, London (2000), pp. 227-235.

[17] M. Steyn, E. Pretorius and L. Hutten, Geometric morphometric analysis of the greater sciatic notch in South Africans, Homo 54 (3) (2004), pp. 197-206.

[18] H. De Villiers, The Skull of the South African Negro, Witwatersrand University Press, Johannesburg (1968).

[19] P.V. Tobias, Growth and stature in Southern African populations. In: D.J.M. Vorster, Editor, Human Biology of Environmental Change, International Biological Programme, London (1972), pp. 96-104.

[20] ISO 7250, Basic human body measurements for technological design, International Organisation for Standardisation, Geneva, 1996.

[21] P.V. Tobias, Stature and secular trend among southern African Negroes and San (Bushmen), S. Afr. J. Med. Sci. 40 (1975), pp. 145-164.

[22] P.V. Tobias and D. Netscher, Reversal of the secular trend, as evidenced by South African Negro crania and femora, Hum. Biol. 59 (1977), pp. 467-475.

[23] P.V. Tobias, The negative secular trend, J. Hum. Evol. 14 (1985), pp. 347-356. 